\title{
Effects of selenium on fatty acid concentration and antioxidant status of erythrocyte membrane in lambs fed linseed or sunflower oil diet ${ }^{*}$
}

\author{
L.L. Yu ${ }^{1}$, J. Cao ${ }^{2}$, X.P. Zhu ${ }^{1}$, W. Zhang ${ }^{1}$ and Z.H. Jia ${ }^{1,3}$ \\ China Agriculture University, \\ ${ }^{I}$ College of Animal Science and Technology, \\ ${ }^{2}$ College of Veterinary Medicine \\ Yuanmingyuan West Road 2, Beijing 100094, P.R. China
}

\begin{abstract}
The effects of selenium and fatty acid supplementation on fatty acid composition and antioxidant status of erythrocyte membrane in lambs were investigated. Thirty two lambs with average body weight of $26 \pm 1 \mathrm{~kg}$ were divided into 4 groups and each was fed basal diet $+5 \%$ linseed oil (LO), or LO+2 mg Se/ $\mathrm{kg} \mathrm{DM}$ (as sodium selenite) (LOSe), or basal diet $+5 \%$ sunflower oil (SO), or $\mathrm{SO}+2 \mathrm{mg} \mathrm{Se} / \mathrm{kg} \mathrm{DM}$ (SOSe). Selenium supplementation increased the concentration of C18:2t-10,c-12, and also the concentration of C20:5n-3 of erythrocyte membrane of the lambs fed the sunflower oil diet. Lambs fed the linseed oil diet had higher concentrations of C18:2t-10,c-12, C18:3n-3, and C20:5n-3 in erythrocyte membrane. Erythrocyte membrane of the lambs fed sunflower oil diet had higher concentrations of C18:1t-11, C18:2n-6, C18:2c-9,t-11 and C22:6n-3. Antioxidant status increased with selenium supplementation, and lambs fed sunflower oil diet had higher total antioxidative capability.
\end{abstract}

KEY WORDS: lamb, selenium, polyunsaturated fatty acid, antioxidant status, erythrocyte membrane

\section{INTRODUCTION}

Many studies have been investigated to increase the content of polyunsaturated fatty acids (PUFA) in lamb tissues by feeding diets supplemented with rumen protected or unprotected oilseed or free oil rich in n-6 or n-3 PUFA. However, diets rich in PUFA lead to higher susceptibility to peroxidation than diets rich

\footnotetext{
* Supported by Chinese National Programs for High Technology and Development Project, Grant No. 2002AA241181

${ }^{3}$ Corresponding author: e-mail: jzh331@cau.edu.cn
} 
in saturated fatty acids. Thus, investigations are needed to combine antioxidants with PUFA in lactating and meat producing ruminants. Selenium (Se) has been shown to affect the fatty acid (FA) composition in mouse muscle and chicken eggs (Czauderna et al., 2004a; Pappas et al., 2005). Information regarding effects of Se on FA composition in sheep is rare (Czauderna et al., 2004b,c), and there were no data published previously about the interaction of PUFA and Se on FA concentration and antioxidant status of erythrocyte membrane. Therefore the objective of the present study was to assess the effects of Se and FA supplementation on FA composition and antioxidant status of erythrocyte membrane in lambs.

\section{MATERIAL AND METHODS}

Thirty-two wether lambs (Chinese Poll Dorset $\times$ Small Tailed Han $\times$ Charolais) with average body weight of $26 \pm 1 \mathrm{~kg}$ divided into four groups and kept in pens individually with free access to water. The experiment was a $2 \times 2$ factorial (two Se levels and two PUFA sources) design. The experimental rations contained either linseed or sunflower oil. The linseed oil diet contained basal diet $+5 \%$ linseed oil (LO) and LO $+2 \mathrm{mg} \mathrm{Se} /$ $\mathrm{kg}$ DM (as sodium selenite) (LOSe). Similarly, the sunflower oil diet contained basal diet $+5 \%$ sunflower oil (SO) and $\mathrm{SO}+2 \mathrm{mg} \mathrm{Se} / \mathrm{kg} \mathrm{DM}$ (SOSe). Lambs were fed $\mathrm{ad}$ libitum with adjustments made on a weekly basis to minimize the amount of orts. Basal feed ingredients and nutrient content were shown in Table 1 . The experiment lasted 50 days. Blood samples from each lamb were obtained by venipuncture from the jugular prior to the morning meal on the last day of the experiment, and then transferred to the tube containing EDTA $(1.5 \mathrm{mg} / \mathrm{ml}$ blood). Erythrocyte membrane was prepared according to the method of Stolze and Nohl (1999). For the FA analysis, the method of Zhang et al. (2006) was used. The total antioxidative capability (TAOC) was measured by the FRAP assay (Benzie and Strain, 1996). The activity

Table 1. The ingredients and chemical composition of the basal diet, DM basis

\begin{tabular}{lrlc}
\hline Ingredients, g/kg & \multicolumn{3}{c}{ Nutrient content $^{1}$} \\
\hline Chinese wild rye hay $^{2}$ & 294.7 & Metabolizable energy, MJ $/ \mathrm{kg}$ & 9.75 \\
Lucerne hay $^{2}$ & 305.3 & Crude protein, g/kg & 146.9 \\
Maize flour $^{2}$ & 168.4 & Acid detergent fibre, g/kg & 284.1 \\
Wheat bran $^{2}$ & 94.7 & Neutral detergent fibre, g/kg & 479.5 \\
Soyabean meal $^{2}$ & 126.3 & Linoleic acid $(\mathrm{C} 18: 2 \mathrm{n}-6), \mathrm{g} / \mathrm{kg}$ & 12.3 \\
Salt $_{\text {Trace mineral premix }}{ }^{3}$ & 5.3 & Linolenic acid $(\mathrm{C} 18: 3 \mathrm{n}-3), \mathrm{g} / \mathrm{kg}$ & 27.5 \\
\hline
\end{tabular}

${ }^{1 .}$ analysed values except metabolizable energy

2. selenium concentration, $\mathrm{mg} / \mathrm{kg}$ DM: Chinese wild rye hay 0.061 , lucerne hay 0.164 , maize flour 0.045 , wheat bran 0.086 , soyabean meal 0.041

3. trace mineral premix contained, $\mathrm{mg} / \mathrm{kg} \mathrm{DM}$ : iodine 1 , iron 40 , copper 9 , cobalt 0.35 , manganese 25 , zinc 40 
of glutathione peroxidase (GSH-Px), and the concentration of malondialdehyde (MDA) were measured according to the methods of Noguchi et al. (1973) and Mak (1983), respectively. All data were analysed as a $2 \times 2$ factorial randomized block design using ANOVA procedure of SAS. When the interaction was significant, pairwise $t$-test was used to separate means by Se within oil source $(\mathrm{P}<0.05)$.

\section{RESULTS AND DISCUSSION}

Selenium supplementation increased $(\mathrm{P}<0.05)$ the concentration of $\mathrm{C} 18: 2 \mathrm{t}-10$, c-12 in erythrocyte membrane (Table 2), which was consistent with that of Czauderna et al. (2004a), who concluded that the interaction between Se and C18:2t-10,c-12 CLA or CLA isomer mixtures exerted its greatest protective effect against peroxidative damage or catabolism of these isomers. The concentration of C20:5n-3 in erythrocyte membrane of the lambs fed sunflower oil supplemented diets was also increased $(\mathrm{P}<0.05)$ with selenium supplementation, but did not affect the eicosapentaenoic acid content of erythrocyte membrane in the lambs fed the diet supplemented with linseed oil. The n-3 PUFA of linseed oil is more susceptible to peroxidation than n-6 PUFA of sunflower oil because of its higher degree of unsaturation (Jin and Miyazawa, 2001). Accordingly, selenium protected

Table 2. Effect of diets on lamb erythrocyte membrane FA composition, $\mathrm{g} / 100 \mathrm{~g}$ total fatty acids

\begin{tabular}{|c|c|c|c|c|c|c|c|c|}
\hline \multirow{2}{*}{ Fatty acid } & \multicolumn{4}{|c|}{ Treatment } & \multirow{2}{*}{ SEM } & \multicolumn{3}{|c|}{ Significance $^{1}$} \\
\hline & LO & LOSe & $\mathrm{SO}$ & SOSe & & $\mathrm{Se}$ & PUFA & $\mathrm{PUFA}^{*} \mathrm{Se}$ \\
\hline C18:0 & 10.61 & 10.83 & 11.27 & 11.03 & 0.21 & ns & ns & Ns \\
\hline C18:1c-9 & 31.82 & 32.33 & 31.30 & 31.37 & 0.35 & ns & ns & Ns \\
\hline C18:1t-11 & 2.26 & 2.43 & 2.69 & 2.83 & 0.08 & ns & $* *$ & Ns \\
\hline C18:2n-6 & 8.01 & 7.70 & 10.64 & 9.36 & 0.39 & ns & $* *$ & Ns \\
\hline C18:2c-9,t-11 & 2.62 & 2.81 & 3.13 & 3.26 & 0.09 & ns & $* *$ & Ns \\
\hline C18:2t-10,c-12 & 0.32 & 0.40 & 0.24 & 0.29 & 0.02 & $*$ & $* *$ & Ns \\
\hline C18:3n-3 & 1.51 & 1.42 & 0.53 & 0.39 & 0.14 & ns & $* * *$ & Ns \\
\hline$C 20: 4 n-6$ & 1.07 & 0.86 & 1.02 & 0.94 & 0.04 & ns & ns & Ns \\
\hline$C 20: 5 n-3$ & 0.45 & 0.42 & $0.18^{\mathrm{b}}$ & $0.31^{\mathrm{a}}$ & 0.03 & $*$ & $* * *$ & $* * *$ \\
\hline$C 22: 6 n-3$ & 7.08 & 7.10 & 7.62 & 8.00 & 0.13 & ns & $* *$ & Ns \\
\hline Total SFA ${ }^{2}$ & 23.16 & 23.37 & 23.79 & 22.44 & 0.30 & ns & ns & Ns \\
\hline Total MUFA ${ }^{2}$ & 35.54 & 36.17 & 35.42 & 35.34 & 0.33 & ns & ns & Ns \\
\hline Total PUFA ${ }^{2}$ & 20.83 & 20.76 & 23.30 & 22.36 & 0.42 & ns & $*$ & Ns \\
\hline
\end{tabular}

${ }^{1}$.ns: not significant, $\mathrm{P}>0.05 ; * \mathrm{P}<0.05 ; * * \mathrm{P}<0.01 ; * * * \mathrm{P}<0.001$

2. SFA: saturated fatty acids, total SFA included C14:0, C16:0, C18:0, C20:0, C22:0, C24:0; MUFA: monounsaturated fatty acids, total MUFA included C14:1, C16:1, C18:1t-11, C18:1c-9, C20:1, C22:1, C24:1; PUFA: polyunsaturated fatty acids, total PUFA included C18:2, C18:2c9,t-11, C18:2t-10,c-12, C18:3, C20:2, C20:3, C20:4, C20:5, C22:6

a,b. means without a common superscript within oil differ significantly at the level of $\mathrm{P}<0.05$ 
the decomposition of C20:5n-3 in lambs fed sunflower oil diet more effectively. This also explained the higher total PUFA concentration of erythrocyte membrane in lambs fed sunflower oil supplemented diet than lambs fed the linseed oil containing diet.

Fatty acids composition of erythrocyte membrane reflects that of other tissues, and also dietary FA composition. The linseed oil diet has higher concentration of C18:3n-3, and the sunflower oil diet has higher concentration of C18:2n-6. Additionally, C18:2 was converted into C18:2c-9,t-11 in the rumen, while C18:2n-6 and C18:3n-3 were converted into C20:4n-6, C20:5n-3 and C22:6n-3, respectively, by serial desaturation and elongation in the tissues. Therefore, lambs fed sunflower oil containing diet had higher $(\mathrm{P}<0.01)$ concentrations of $\mathrm{C} 18: 2 \mathrm{n}-6$ and $\mathrm{C} 18: 2 \mathrm{c}-9, \mathrm{t}-11$, and those were fed with linseed oil diet had higher $(\mathrm{P}<0.001)$ concentrations of $\mathrm{C} 18: 3 \mathrm{n}-3$ and $\mathrm{C} 20: 5 \mathrm{n}-3$. Interestingly, the concentration of C20:4n-6 in erythrocyte membrane showed no difference between lambs fed linseed or sunflower oil diet, and sunflower oil diet resulted higher concentration of $\mathrm{C} 22: 6 \mathrm{n}-3(\mathrm{P}<0.01)$. This was probably caused by the average life-span of the erythrocytes, usually 4-5 months, and the dietary changes of C20:4n-6 and C22:6n-3 fatty acids concentration of erythrocyte membranes lasted only for 50 days.

Selenium is a part of the active center of GSH-Px, which catalyzes the reduction of peroxides. MDA is a meta-stable end product of lipid peroxidation.

Table 3. Effect of diets on the antioxidant status of erythrocyte membrane

\begin{tabular}{|c|c|c|c|c|c|c|c|c|}
\hline \multirow{2}{*}{ Item } & \multicolumn{4}{|c|}{ Treatment } & \multirow{2}{*}{ SEM } & \multicolumn{3}{|c|}{ Significance $^{1}$} \\
\hline & $\mathrm{LO}$ & LOSe & $\mathrm{SO}$ & SOSe & & $\mathrm{Se}$ & PUFA & PUFA*Se \\
\hline \multicolumn{9}{|c|}{ Total antioxidative capability } \\
\hline $\mathrm{U} / \mathrm{mg}$ protein & 0.98 & 1.20 & 1.19 & 1.34 & 0.04 & $* *$ & $* * *$ & ns \\
\hline \multicolumn{9}{|c|}{ Glutathione peroxidase activity } \\
\hline $\mathrm{U} / \mathrm{mg}$ protein & 81.74 & 118.90 & 81.42 & 110.34 & 5.79 & $* *$ & ns & ns \\
\hline $\begin{array}{l}\text { Malondialdehyde } \\
\text { nmol/mg protein }\end{array}$ & 1.34 & 0.89 & 0.95 & 0.65 & 0.07 & $* * *$ & $* * *$ & ns \\
\hline
\end{tabular}

${ }^{1}$.ns: not significant, $\mathrm{P}>0.05 ; * \mathrm{P}<0.05 ; * * \mathrm{P}<0.01 ; * * * \mathrm{P}<0.001$

In present study the selenium supplementation increased $(\mathrm{P}<0.01)$ the activity of GSH-Px and TAOC, and decreased $(\mathrm{P}<0.001)$ the concentration of MDA in erythrocyte membrane (Table 3). Erythrocyte membrane of lambs fed sunflower oil diet had higher $(\mathrm{P}<0.001)$ concentration of TAOC and lower $(\mathrm{P}<0.001)$ concentration of MDA than those fed linseed oil diet, which indicated the higher degree of unsaturation of n-3 PUFA than n-6 PUFA. 


\section{REFERENCES}

Benzie I.F.F., Strain J.J., 1996. The ferric reducing ability of plasma (FRAP) as a measure of "antioxidant power": the FRAP assay. Anal. Biochem. 239, 70-76

Czauderna M., Kowalczyk J., Niedźwiedzka K.M., Wąsowska I., Pastuszewska B., 2004a. Conjugated linoleic acid (CLA) content and fatty acids composition of muscle in rats fed isomers of CLA and selenium. J. Anim. Feed Sci. 13, 183-196

Czauderna M., Kowalczyk J., Niedźwiedzka K.M., Wąsowska I., Pająk J.J., 2004b. The effect of selenium and linseed oil on growth of sheep and content of selected fatty acids in M. longissimus dorsi. J. Anim. Feed Sci. 13, Suppl. 1, 303-306

Czauderna M., Kowalczyk J., Niedźwiedzka K.M., Wąsowska I., Pająk J.J., Bulska E., Ruszczyńska A., 2004c. The effect of linseed oil and selenium on the content of fatty acids and some elements in the liver and selected tissues of sheep. J. Anim. Feed Sci. 13, Suppl. 2, 105-108

Jin H.S., Miyazawa T., 2001. Ehanced level of n-3 fatty acid in membrane phospholipids induces lipid peroxidation in rats fed dietary docosahexaenoic acid oil. Atherosclerosis 155, 9-18

Mak M.I., Misra H.P.,Weglicki W.B., 1983. Temproal relationship of free radical-induced lipid perocidation and loss of latent enzyme activity in highly enriched hepatic lysosomes. J. Biol. Chem. 258, 13733-13737

Noguchi T., Cantor A.H., Scott M.L., 1973. Mode of action of selenium and vitamin E in prevention of exudative diathesis in chicks. J. Nutr. 103, 1502-1511

Pappas A.C., Acamovic T., Sparks N.H.C., Surai P.F., McDevitt R.M., 2005. Effects of supplementing broiler breeder diets with organic selenium and polyunsaturated fatty acids on egg quality during storage. Poultry Sci. 84, 865-874

Stolze K., Nohl H., 1999. Free radical formation and erythrocyte membrane alterations during $\mathrm{MetHb}$ formation induced by the BHA metabolite, tert-butylhydroquinone. Free Radical Res. 30, 295-303

Zhang Y.Z., Kong X.H., Zhu X.P., Wang R.L., Yan Y.C., Jia Z.H., 2006. Effect of forage to concentrate ratio and monensin supplementation on cis-9,trans-11 conjugated linoleic acid and trans-11 octadecenoic acid concentrations of ruminal contents and plasma in sheep. Asian-Austr. J. Anim. Sci. 19, 699-704 